\title{
System Theory for an Information system for planning project activities in a high-tech enterprise
}

\author{
Marina Batova, \\ Department of Informatics and Management, \\ Military University of the Ministry of Defense \\ of the Russian Federation, \\ 14, Bolshaya Sadovaya st., Moscow, 125047, \\ Russia, \\ Oleg Korobchenko, \\ General Director, \\ Korib Group of Companies, \\ 55, Industrialny proezd str., Naberezhnye Chelny, \\ Republic of Tatarstan, 423800, \\ Russia
}

\author{
Irina Baranova, \\ Department of Business and \\ Business Administration, \\ Russian Presidential Academy of National Economy \\ and Public Administration, \\ 82, prospect Vernadskogo, Moscow, 119571, \\ Russia \\ Vyacheslav Baranov \\ Department of Business and \\ Business Administration, Russian Presidential \\ Academy of National Economy and Public \\ Administration, 82, prospect Vernadskogo, Moscow, \\ 119571, Russia
}

Received: July 21, 2020. Revised: February 25, 2021. Accepted: March 11, 2021. Published: March 18, 2021.

\section{INTRODUCTION}

\begin{abstract}
Financial Systems and Financial Engineering plays an important role in modern Systems Theory. In Systems Theory, the planning and informatization issues concerning project management processes in high-tech enterprises have been considered. The network model role in organizing the intellectual resource management of an innovative project was investigated. A set of heuristic preference rules for organizing project management under conditions of limited intellectual resources available for the project was developed. An algorithm for constructing an implementation schedule for an innovation project as well as for estimating the dynamics of resource consumption and loss depending on the presence or absence of constraints on the project intellectual resource value was proposed. A description is given for a software product created by the authors, providing support for decisions made by the high-tech enterprise management at the stage of project operational and calendar planning of its intellectual resources.
\end{abstract}

Keywords-Applied Systems Theory, Financial Systems, Systems Engineering, Systems Theory, Heuristic preference rules, innovation project, network model, oriented graph, project management.
$\mathrm{O}$ NE of the most Important Part in Modern Systems Theory is the Financial Systems Theory and Financial Engineering. the digital economy's paradigms is the concept of project management development based on process approach technologies. When applying the process approach technologies, Russian companies are actively creating corporate project management systems [1]. At that, the created systems are based, as a rule, either on flexible (Agile) [2]-[4], or cascade (Waterfall) model [5]. This approach is most relevant for high-tech enterprises, as these enterprises are focused on innovative activities characterized by a high level of uncertainty in their external and internal environment, as well as the risk of failure to obtain the planned results [6]-[9]. In addition, innovation activities require a significant amount of financial, material and information-intellectual resources. Therefore, the innovation project management [10] is usually carried out in a resource-constrained environment. Limited innovation project resources have an impact on the timing of its development and implementation, and ultimately, on the competitiveness of the project activity results. For example, an increase in the time required to bring to the market the technological innovations (primarily, qualitatively new products and technologies) created within an innovation project may cause a high-tech enterprise to lose its competitive advantage. Therefore, the task of allocating limited resources to the stages and phases of the innovation project in progress becomes the most relevant for those enterprises (Figure 1). 


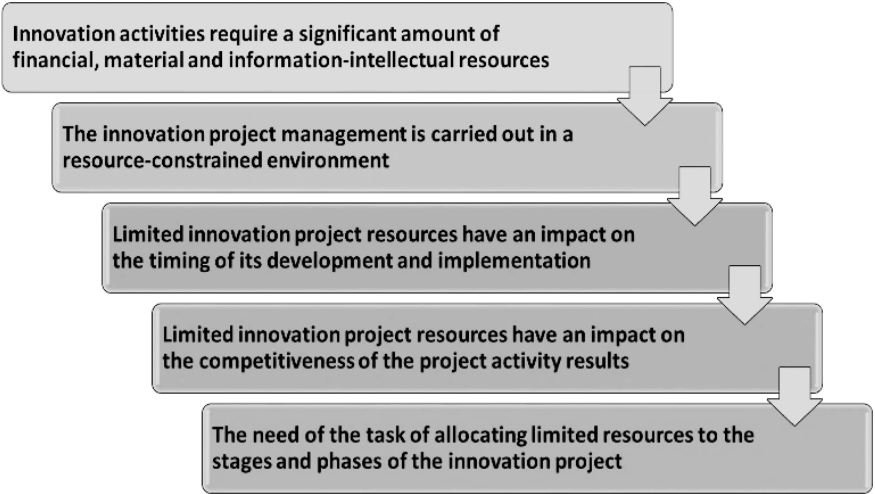

Fig.1. Scheme of relevance of a task of allocating limited resources. Source: author's research.

Developing an innovation project management strategy, a high-tech enterprise uses re-engineering methods and designs qualitatively new business processes. The implementation of these processes is monitored at the tactical and operational levels of project management. The level of complexity of the projected business processes requires automation achieved through robotization and the use of information systems. Automation is a costly measure, both financially and intellectually [1], [11]. And, quite often, it is the intellectual component of capital that is the more important factor [12].

Value and quality of an intellectual capital ensuring the effective implementation of an innovation project is formed through implementing the following measures.

- Firstly, by attracting highly qualified specialists with high professional competences [12], [13].

- Secondly, it takes place due to using various information systems in the project management [7], [14], [15].

Plan, Suretrak Project Manager, Primavera Project Planner, Spider Project, Libre Project, etc. are used in the project management [16]. The implementation of these measures leads to the appearance of the information-intellectual component in the structure of high-tech enterprise assets. This component becomes the key success factor of project management in the information society.

The choice of best option for resource allocation is based on project management tools such as Project Management Body of Knowledge (PMBoK) and Organizational Project Management Maturity Model (OPMMM) [5], [17], [18] (Figure 2).
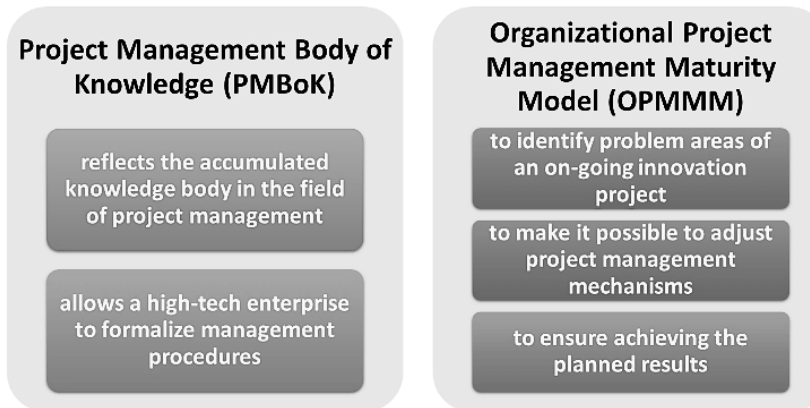

Fig.2. Scheme of the main features of PMBoK and OPMMM for the choice of best option for resource allocation.

Source: author's research.
Through reflecting the accumulated knowledge body in the field of project management, Project Management Body of Knowledge allows a high-tech enterprise to formalize management procedures. Organizational Project Management Maturity Model is a tool due to which a high-tech enterprise can identify problem areas of an on-going innovation project. Identification of these areas makes it possible to target the problem factors and, by adjusting project management mechanisms, ensure achieving the planned results. Such mechanisms are especially necessary for intellectual resource management, which quality and efficiency becomes a key factor in the success of high-tech enterprise's project activities.

In this situation, the relevance of using such tools that would contribute to the best achievement of the project goals is increased. Such tools should provide not only a timely response to the changes in the project external and internal environment, but also make it possible to develop predictive estimates of these changes. First of all, this concerns the processes of complex science-intensive project development that require coordination of the activities of numerous performers, linking interrelated works of various profiles into a single system. The solution to this problem allows us to consider the process of planning project activities as an inextricable complex of interrelated operations aimed at the ultimate goal achievement, and project participants as the links of a single complex system. Besides, it becomes possible to manage project resources effectively, including intellectual and time resources.

The use of modern project management tools is based on strict logical elements of the schedule development and the project schedule. This approach to project management makes it possible to use modern mathematical apparatus to model the processes of project implementation and analyze the results obtained, as well as to use information systems and technologies. Such factors as increasing complexity and strengthening the innovative focus of projects have necessitated a transition to more efficient and informative methods of project activity planning. The key aspects of efficiency are the informatization of business processes occurring within the framework of project activities, minimization of the cost component duration concerning the project life cycle, rational use of available resources, primarily the intellectual component of these resources.

\section{PRoBlem Statement}

The need for effective and efficient use of intellectual resources in an innovation project is dictated by the situation in the markets for high-tech and knowledge-intensive products. In the current environment, not only the formation of new segments in the existing markets, but also the creation of future markets becomes a significant factor in the strategic competitiveness of high-tech enterprises. The solution to this problem requires increasing the knowledge content of the created products, giving them qualitatively new properties and functions. This requires not only optimising the resource consumption and reducing the duration in the life cycle's cost 
part of an innovation project, but also to change the cost structure by increasing its intellectual component. This is achieved by applying modern management methods, techniques and technology, in particular, the network modelling method [19]-[21]. The use of this method, which meets the requirements of the cybernetic approach to the complex dynamic systems management, allows a high-tech enterprise to optimize the expenditure of intellectual resources and ensure a high efficiency and effectiveness level for project activities.

The solution to the problem of allocating intellectual project resources by the works to be performed is to build a schedule [21]-[23], which allows ensuring minimum resource loss under the condition of completing the project in the shortest possible time. Solving such a task is very time-consuming. Therefore, another task arises: it is necessary to create an original software application which takes into account the specifics of high-tech enterprise activities, as well as the specifics of the innovative project implemented by the enterprise.

\section{PROBLEM SOLUTION}

\section{A. Intellectual Resource Management in the System of Operational and Calendar Planning}

The process of the resource distribution in time and space required by a high-tech enterprise to carry out an innovative project is implemented using the mechanism of operational scheduling. In relation to strategic management, which is carried out at the upper hierarchical level, operational scheduling in the project management system is implemented at the next, lower level of the hierarchy. At this level, the methods and tools of operational scheduling allow for the implementation of an innovative project by distributing the resources attracted by a high-tech enterprise in an optimal way, to ensure its effective implementation. Using the network modeling methodology for the purposes of this task formalization, which is based on the construction and analysis of oriented graphs, makes it possible to increase the visibility of the project management process, in particular, to make the project resource planning process more informative in time and space.

In this case, the business processes occurring within the framework of the innovative project can be described using an oriented graph that combines the interconnected project activities into a single system, each of which is associated with the duration and size of the applied resource. Then the oriented graph describing the innovative project will consist of a finite number of vertices and oriented arcs. An arc of a oriented graph characterizes the process of performing specific actions within a project. The moments of the beginning and the end of these actions form the vertices of the graph. The vertices of the graph are considered as events, and the arcs of the graph as the work of the project.

In the project resource planning system, the oriented graph acting as a graphical way for in time mapping the individual activities, simple and complex processes carried out within the framework of an innovation project, provides a number of advantages to a high-tech enterprise. In particular, the formalization of input information makes it possible to organize effective and efficient monitoring during the implementation of an investment project.

The demand for intellectual resources required for implementing an innovation project is characterized by the resource consumption intensity per time unit. In different project implementation scenarios, the resource consumption intensity per time unit is usually different. A change in the resource consumption intensity quite often leads to a change in the time parameters of the project. Changes in these parameters are associated with changes in the duration of the corresponding set of works at this or that project implementation stage (Figure 3).

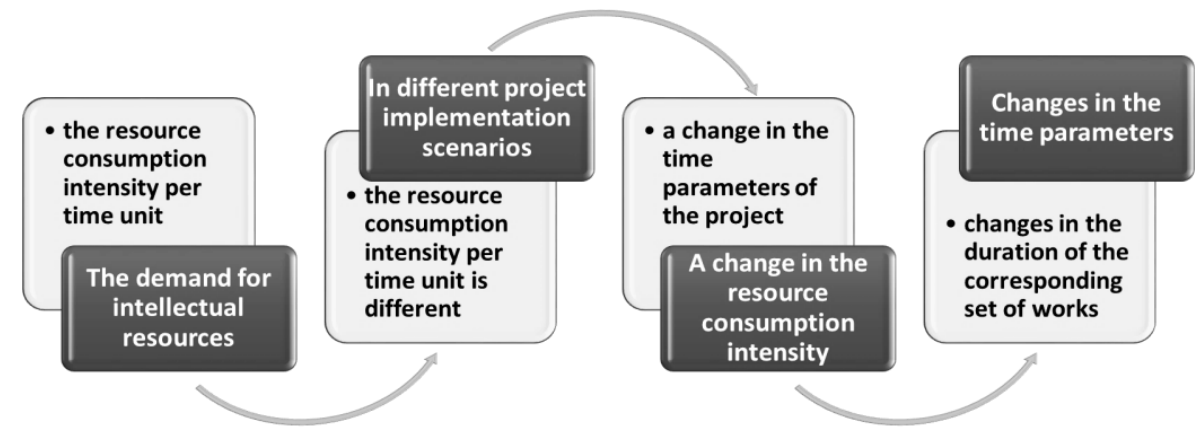

Fig.3. Diagram of the need to manage intellectual resources using operational and calendar planning.

Source: author's research.

Intellectual resource management in the system of operational and calendar planning is performed as follows (Figure 4). First of all, a network model is built, which is an oriented graph. In this model, the arcs are business processes implemented within the framework of the project. Then the model parameters that characterize the vertices' and arcs' state of an oriented graph in time are calculated. The graph vertices are considered as events, and the graph arcs are considered as network model activities. These parameters characterise the vertices (events) and the arcs of the graph (network model's works). The most important parameters include the early $\left(T^{\text {ear }}\right)$ and late $\left(T^{\text {lat }}\right)$ timing of the preceding $i$-th and succeeding $j$-th 
network model events, the early finishes of the $i$-th work $\left(t_{i j}{ }^{\text {ear }}\right.$ fin $)$, the late start of the $i$-th work $\left(t_{i j}^{\text {lat.st }}\right)$, the event time reserve $(R)$, the particular $\left(R_{i j}{ }^{\text {part }}\right)$ and total $\left(R_{i j}^{\text {tot }}\right)$ time reserves of the $i j$-th work.

Then a schedule is constructed for a set of project activities, which represents the relative start and end times of each activity in the oriented graph. These times are calculated on the assumption that the current time is zero at the start of the operational scheduling. This assumption is made for the convenience of the oriented graph parameter calculation. After calculating these parameters and building a schedule in relative time units, a calendar schedule for the implementation of an innovative project is formed. The project schedule will be a binding of the received schedule to the actual calendar period of time. This means the removal of the initially made assumption, according to which the initial moment of planning was equated to zero. In the timetable, this starting moment is identified with the actual calendar date of the project start. Then the early date of the final event completion, which coincides with its late date, will reflect the calendar date of the project completion.

The algorithm for scheduling depends:

- firstly, on the presence or absence of constraints on the project's intellectual resource and,

- secondly, on the possibility of changing the intensity of consumption of this resource over time.

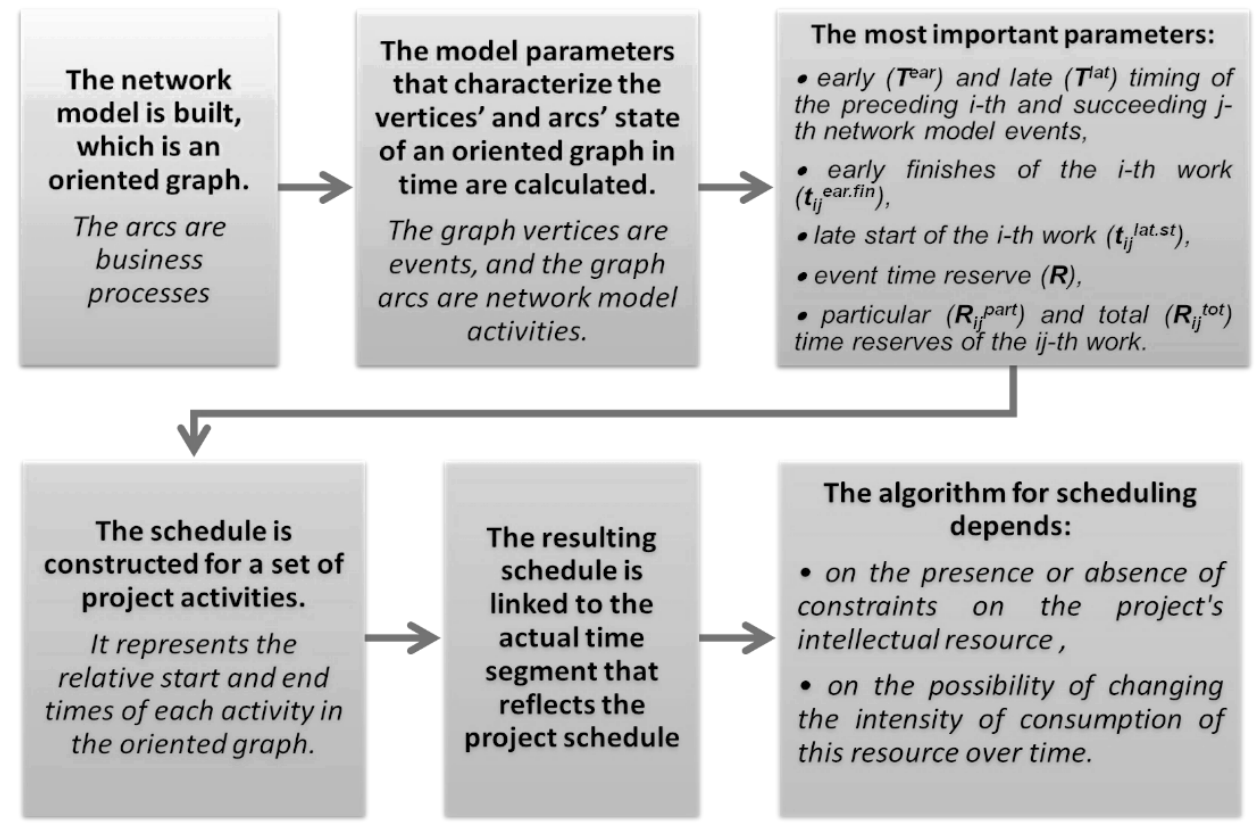

Fig.4. Pattern of performed intellectual resource management in the system of operational and calendar planning.

Source: author's research.

If the project's intellectual resource is unconstrained, any $i j$-th work is considered acceptable for inclusion in the schedule at time $t$ if the $i$-th event preceding it has occurred by this time. The schedule duration will be minimal if all events of the network model occur at their earliest times. In the absence of resource constraints, the schedule duration will be equal to the duration of the critical path, which has the maximum duration.

The constraint on the intellectual resource of an innovation project complicates the solution to the optimal resource allocation problem for activities in an oriented graph. In this case, it is necessary to form heuristic preference rules and build in a system that allows prioritizing each activity when it is included in the schedule.

Construction of the total intellectual resource consumption intensity graph and evaluation of losses are based on summing the resource consumption intensity by all the activities simultaneously performed at one or another point in time. This summation is performed on a time interval equal to the schedule duration. In the absence of constraints, the resource loss is as follows:

$$
Q_{z}=\int_{0}^{z}\left(Q_{\max }(t)-Q(t)\right) d t
$$

Where $z$ is the schedule duration of the project's work package; $Q(t)$ is the resource value consumed upon the project execution at time $\mathrm{t}$, and $Q_{\max }(t)$ is the maximum consumption of this resource

When solving the constrained resource management problem, the maximum value of the resource consumed during the project execution will not exceed the available resource. The resulting resource loss will be:

$$
Q_{z}=\int_{0}^{z}\left(Q_{\text {const }}-Q(t)\right) d t
$$

Where $Q_{\text {const }}$ is a time constant value of the project 
intellectual resource.

Thus, to solve the problem of effective resource planning for an innovative project, including scheduling and assessing the loss of intellectual resources, an appropriate algorithm was proposed (Figure 5), which is implemented as the following sequence of steps:

Step 1: the whole range of business processes implemented within the framework of the innovative project is described as a set of works, each of which is assigned the start and end times ( $i$-th and $j$-th events).

Step 2: for each $i j$-th work from the entire set of works performed within the framework of the innovation project, the labor intensity $\left(\tau_{i j}\right)$, the duration of execution $\left(t_{i j}\right)$ and the amount of intellectual resource consumed by the work $\left(q_{i j}\right)$ are determined.

Step 3: they set a limit on the amount of the project intellectual resource $\left(Q_{\text {const }}\right)$.

Step 4: they determine the relationship between the works, and taking into account the identified relationship, a oriented graph is built.

Step 5: the parameters of the oriented graph are calculated (an example of such a calculation is presented in Table 1).

Step 6: a set of preference heuristic rules is developed and a preference heuristic scheme is built.

Step 7: a schedule for the implementation of a complex of works of an innovative project is built, the relationship of which is given by a oriented graph.

Step 8: based on the resulting schedule, they create a timetable for the implementation of the innovative project.

Step 9: they develop a graph of the total intensity of an intellectual resource consumption by an innovative project work.

Step 10: measures are designed to optimize the schedule duration and the loss of the innovative project intellectual resource.

\begin{tabular}{|c|c|}
\hline & $\begin{array}{l}\text { - dicription of a set of works } \\
\text {-start and end times: } i \text {-th and } j \text {-th events }\end{array}$ \\
\hline & $\begin{array}{l}\text { - labor intensity } \tau_{i j} \\
\text {-duration of execution } t_{i j} \\
\text { - amount of intellectual resource consumed by the work } q_{i j}\end{array}$ \\
\hline & $\begin{array}{l}\text { - limit on the amount of the project intellectual resource } \\
Q_{\text {const }}\end{array}$ \\
\hline & $\begin{array}{l}\text {-relationship between the works } \\
\text { •bilding an oriented graph }\end{array}$ \\
\hline s & - calculation of the parameters of the oriented graph \\
\hline & $\begin{array}{l}\text {-development of a set of preference heuristic rules } \\
\text {-bilding a preference heuristic scheme }\end{array}$ \\
\hline & $\begin{array}{l}\text {-bilding a schedule for the implementation of a complex of } \\
\text { works of an innovative project }\end{array}$ \\
\hline & $\begin{array}{l}\text { - creation of a timetable for the implementation of the } \\
\text { innovative project }\end{array}$ \\
\hline St & $\begin{array}{l}\text { - construction of a graph of the total intensity of an } \\
\text { intellectual resource consumption by an innovative project } \\
\text { work }\end{array}$ \\
\hline Step10 & $\begin{array}{l}\text {-optimization of the schedule duration and the loss of the } \\
\text { innovative project intellectual resource }\end{array}$ \\
\hline
\end{tabular}

Fig.5.Algorithm of effective resource planning for an innovative project.

Source: author's research.

The implementation of the measures leads to the need to change the topology of the oriented graph and perform new calculations according to the algorithm described by us.

In the case of implementing several projects, a generalized schedule is formed, for the construction of which it is advisable to apply dynamic preference rules. Such rules are focused on the use of dynamic time reserve of the $i j$-th work $\left(R_{i j}^{g}\right)$, which value will be:

$$
R_{i j}^{g}=D-t_{i j}^{\text {lat.st }}-t_{i j}
$$

Where $D$ is the planned completion date of a set of all works performed within the framework of various projects; $t_{i j}^{\text {lat.st }}$ is the late start of the $i j$-th work, and $t_{i j}$ is its duration.

The resulting schedule and the schedule prepared on its basis are used to monitor the project activities of a high-tech enterprise implementing several projects.

\section{B. Developed Software for Support and Decision-Making at the Operational and Calendar Planning Stage}

To improve the intellectual resource management quality of an innovation project, we have developed a software product that provides support for decisions made by the high-tech enterprise management at the operational and calendar planning stage. The range of these decisions includes construction of the project implementation schedule, construction of the schedule reflecting the total intensity of intellectual resource consumption and assessment of losses of 
this resource. The use of the developed software application gives an opportunity to obtain a spectrum of schedules and intellectual resource loss estimations by changing the initial data of project business processes. Based on analysis of the obtained options, the decision on the best option choice is made. The developed software application meets the requirements of international project management standards taking into account the features and specific activities of a high-tech enterprise. The developed software package has prospects for expanding its functionality when organising a portfolio management for a set of innovation projects. The Figure 6 shows the main features of the developed software.
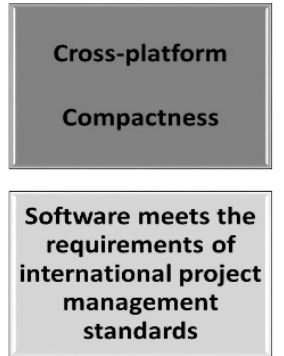

Multi-functional integrated development environment IntelliJ IDEA
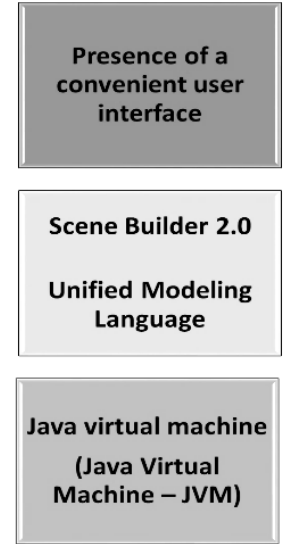

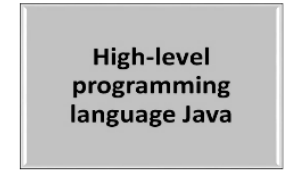

Architecture of the software Model-ControllerView

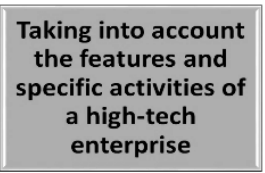

Fig.6. Diagram of the main features of the developed software. Source: author's research.

When developing the software package, the high-level programming language Java was used [24]-[30]. The software application written in high-level Java language can be implemented in different operating environments, in particular, Windows, Linux, Macintosh Operating System, etc. This is ensured by using the Java Virtual Machine (JVM), which executes the Java byte code. The software package is implemented in the feature-rich IntelliJ IDEA integrated development environment. It is a functional and ergonomic environment for JVM; it analyses the monotonous tasks involved in software application development and automates the execution processes for these tasks. The IntelliJ IDEA environment is compatible with common open source software such as CVS, Subversion, Apache Ant, Junit, etc. The sixth and subsequent versions of the product IntelliJ IDEA includes integrated development tools to develop an easy-to-use graphical user interface. In addition, the IntelliJ IDEA development environment implements intuitive autocompletion. The environment includes a debugging toolkit for debugging programs.

The software package is created using the JavaFX platform [26], [28], which, with its extensive functionality, is used to develop software applications with a rich graphical user interface. The user interface is developed using Scene Builder 2.0 software [27], [28]. Scene Builder 2.0 is a tool which can be used to build and save different windows as a graphical user interface. Using the result obtained, program constructs fxml files with formal user interface description.
The created software package architecture, covering many program elements, is quite branched. The element composition of the architecture is focused on the Model-View-Controller (MVC) design pattern [11]. The Model encompasses a set of subject area classes. Involving the Unified Modeling Language, which provides a unique and direct graphical notation, allows for a visual representation of the system state. The linking role of Model and View in a software package is played by Controller. The View provides a user-friendly interface as an element of the software application.

For the practical application of the software package, an interface has been designed to guarantee maximum userfriendliness to the user. At the beginning, the raw data for the construction of the schedule is generated. For this purpose, the project manager generates a list of activities to be carried out within the project. For each activity, the preceding $i$-th and subsequent $j$-th events are established, and the activity duration and the intellectual resource provision level are estimated.

When implementing the project management strategy, a project manager is often faced with the situation when the baseline data within the project under implementation are changed. This may concern a change in the $i j$-th work duration or the intensity of an intellectual resource consumption by any work. For this case, the software application has an editing function.

The emergence of additional activities within the project being implemented by a high-tech enterprise means the addition of new elements to the list of activities. The "Add work" function is available for this operation. Correspondingly, the inverse operation, involving the deletion of works which are not relevant to the project from the list, is implemented with the help of the "Delete work" function. When the list of works has been changed, a user of the project application (project manager) generates new baseline data for the newly created variants of the project. Using the updated source data, the software application constructs a new schedule and a graph of the total intensity of intelligent resource consumption, on the basis of which the resource loss is estimated.

\section{RESULTS AND DISCUSSION}

Using a hypothetical example, let us consider formalising the intellectual resource management processes of an innovation project based on graph theory [31]. A high-tech enterprise develops an innovation project that prepares the production of product innovations. Two variants of solving this problem are considered. The first variant assumes that the value of intellectual resource of the project is not limited. The second variant assumes the presence of a limit on the value of intellectual resource. The value of this limit is determined by the number of project implementers and is 4 people.

First, the project manager enters the initial data necessary to build a network model necessary for management of intellectual resources of the project at the preparation stage for production of product innovations. Then a network model of 
intellectual resource management for the pre-production phase of a product innovation is constructed (Figure 7).

In this figure, each $i j$-th work of the network model is characterized by its duration $t_{i j}$, which is denoted by a number without brackets, and the intellectual resource consumption intensity $q_{i j}$, which is denoted by a number in brackets.

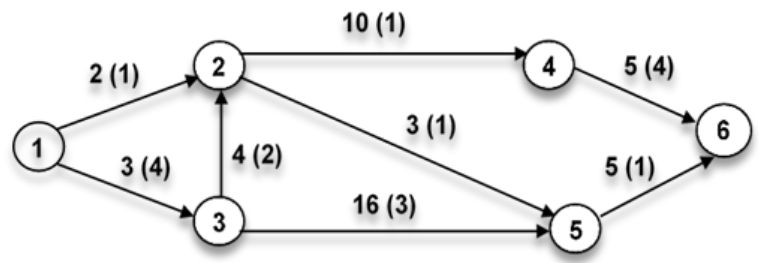

Fig.7. A network model describing the preparing process for the production of product innovations.

Source: author's research.

Then the software calculates the network model parameters.

The early timing of event occurrence in the network model is calculated sequentially, moving from the initial event to the final event. The early onset of the next $j$-th event $\left(T_{j}^{e a r}\right)$ is the sum of the early onset of the initial event of the model $\left(T_{b}{ }^{e a r}\right)$ and the maximum duration of the path from the initial event to the $j$-th event $\left(\max \left\{Z_{\text {st. }}\right\}\right)$. In this case, the duration of the path is determined on the basis of the assumption that all events and all work that lie on this path begin at their early dates. Then this ratio can be written as follows:

$$
T_{j}{ }^{e a r}=T_{b}{ }^{e a r}+\max \left\{Z_{s t . j}\right\}
$$

When calculating the early timing of events, it was assumed that the early timing of the initial event in the network model is zero, i.e. $T_{b}{ }^{e a r}=0$.

Late timing of events is calculated in reverse order within the network model, i.e. from the end event to the start event. The late onset of the preceding $i$-th event $\left(T_{i}^{l a t}\right)$, which is the late onset of the final event $\left(T_{k}^{\text {lat }}\right)$ minus the maximum travel time from the $i$-th event to the final event. This duration is calculated on the assumption that all events and works that lie along the way end at their later dates. Then this ratio can be written as follows:

$$
T_{i}^{\text {lat }}=T_{k}^{\text {lat }}-\max \left\{Z_{\text {st. } j}\right\}
$$

When calculating the late timing of the event start of the oriented graph, it was assumed that the early and late timing of the final event coincide. This means that $T_{k}^{l a t}=T_{k}^{e a r}$.

The time reserve of the $j$-th event $\left(R_{j}\right)$ is the time interval for which the occurrence of this event can be delayed, provided that the final event occurs at its later date. Then:

$$
R_{j}=T_{j}^{l a t}-T_{j}^{e a r}
$$

The early completion date of the $i j$-th work $\left(t_{i j}^{e a r}\right.$.fin $)$ is the sum of the early completion date of the previous $i$-th event $\left(T_{i}^{\text {ear }}\right)$ and the duration of this work $\left(t_{i j}\right)$.

$$
t_{i j}{ }^{e a r} \cdot \text { fin }=T_{i}^{e a r}+t_{i j}
$$

The late start date of the $i j$-th work $\left(t_{i j}^{\text {lat.st }}\right)$, is the late date of the onset of the next $j$-th event $\left(T_{j}^{\text {lat }}\right)$ minus the duration of this work $\left(t_{i j}\right)$.

$$
t_{i j}^{\text {lat.st }}=T_{j}^{\text {lat }}-t_{i j}
$$

The particular reserve of time for the $i j$-th work $\left(R_{i j}{ }^{\text {part }}\right)$ is the time interval for which the start can be delayed or the duration of the $i j$-th work can be increased, provided that the subsequent $j$-th event occurs at its early date. Then we get the following expression:

$$
R_{i j}^{\text {part }}=T_{j}^{\text {lat }}-t_{i j}^{\text {ear } f \text { fin }}
$$

The total-time reserve for the $i j$-th work $\left(R_{i j}{ }^{\text {tot }}\right)$ is the time interval by which the start can be delayed or the duration of the $i j$-th work can be increased, provided that the subsequent $j$ th event occurs at its later date. Then the following relation takes place:

$$
R_{i j}^{\text {tot }}=R_{i j}^{\text {part }}+R_{j}=T_{j}^{\text {lat }}-t_{i j}^{\text {ear } f \text { in }}
$$

The results of calculating the parameters of the network model for the project intellectual resource management at the stage of product innovation preparation are shown in Table 1.

Table 1

Parameters describing the network model for project intellectual resource management at the preparation stage for production of product innovation

\begin{tabular}{|c|c|c|c|c|c|c|c|c|c|c|}
\hline $\boldsymbol{i}$ & $\boldsymbol{j}$ & $\boldsymbol{T}_{\boldsymbol{i}}^{\text {ear }}$ & $\boldsymbol{t}_{\boldsymbol{i}}{ }^{\text {ear.fin }}$ & $\boldsymbol{T}_{\boldsymbol{j}}^{\text {ear }}$ & $\boldsymbol{T}_{\boldsymbol{i}}^{\text {lat }}$ & $\boldsymbol{t}_{\boldsymbol{i} \boldsymbol{j}}^{\text {lat.st }}$ & $\boldsymbol{T}_{\boldsymbol{j}}^{\text {lat }}$ & $\boldsymbol{R}_{\boldsymbol{j}}$ & $\boldsymbol{R}_{\boldsymbol{i}}{ }^{\text {part }}$ & $\boldsymbol{R}_{\boldsymbol{i}}^{\text {fot }}$ \\
\hline 1 & 2 & 0 & 2 & 7 & 9 & 7 & 0 & 2 & 5 & 7 \\
\hline 1 & 3 & 0 & 3 & 3 & 3 & 0 & 0 & 0 & 0 & 0 \\
\hline 2 & 4 & 7 & 17 & 17 & 19 & 9 & 9 & 2 & 0 & 2 \\
\hline 2 & 5 & 7 & 10 & 19 & 19 & 16 & 9 & 0 & 9 & 9 \\
\hline 3 & 2 & 3 & 7 & 7 & 9 & 5 & 3 & 2 & 0 & 2 \\
\hline 3 & 5 & 3 & 19 & 19 & 19 & 3 & 3 & 0 & 0 & 0 \\
\hline 4 & 6 & 17 & 22 & 24 & 24 & 19 & 19 & 0 & 2 & 2 \\
\hline 5 & 6 & 19 & 24 & 24 & 24 & 19 & 19 & 0 & 0 & 0 \\
\hline
\end{tabular}

Source: author's research.

Further, using the calculation results, the program builds a schedule, which is a graphical representation of the data shown in Table 1. With the absence of restrictions on intellectual resources, the project schedule is shown in Figure 8. The schedule was built as follows. At the initial moment of time $(\mathrm{t}=0)$, the works $\mathbf{1 - 3}$ and $\mathbf{1 - 2}$ apply for inclusion in the schedule. Since the intellectual resource of the project is not limited, there is no conflict between these works. Therefore, these works are included simultaneously in the schedule. After completion of the work 1-3, the 3rd event occurs. After the onset of the 3rd event, the work 3-5 is included in the schedule, which belongs to the critical path with the maximum duration.

To complete the 2 nd event, it is necessary to perform the work 3-2, which is included in the schedule at the same time as the work 3-5, since there will be no conflict between the works due to the unlimited resource. It can be seen from the figure that the work 1-2 has a particular time reserve of 5 days, which corresponds to the results of calculations presented in Table 1. After the completion of the 2nd event, the work 2-4 and 2-5 are included in the schedule, which are performed 
simultaneously with the work 3-5. The moment of the work 24 completion corresponds to the onset of the 4 th event, and the moment of the work 3-5 completion corresponds to the onset of the 5th event. Figure 7 shows that the work 2-5 has a particular reserve of time, the value of which is 9 days. After the onset of the 4th event, the work 4-6 begins, the particular reserve of which is 2 days. When the 5 th event is completed, the schedule includes the work 5-6 belonging to the critical path. Thus, from Figure 8, it can be seen that the duration of the schedule, equal to 24 days, was determined by the duration of the critical path work.

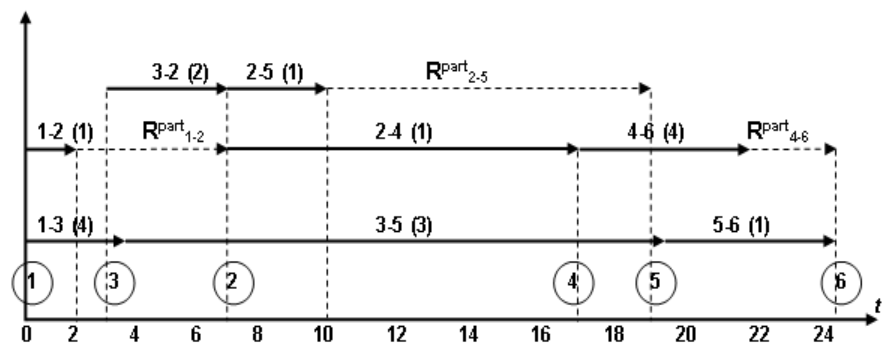

Fig.8. Timetable characterising the preparation process for production of product innovation in the absence of project resource constraints.

Source: author's research.

By summing up the intellectual resource consumption intensity by all activities simultaneously performed at time t, the graph (Figure 9) of intellectual resource consumption intensity of the project is plotted and the value of resource loss, which is 60 man-days, is determined.

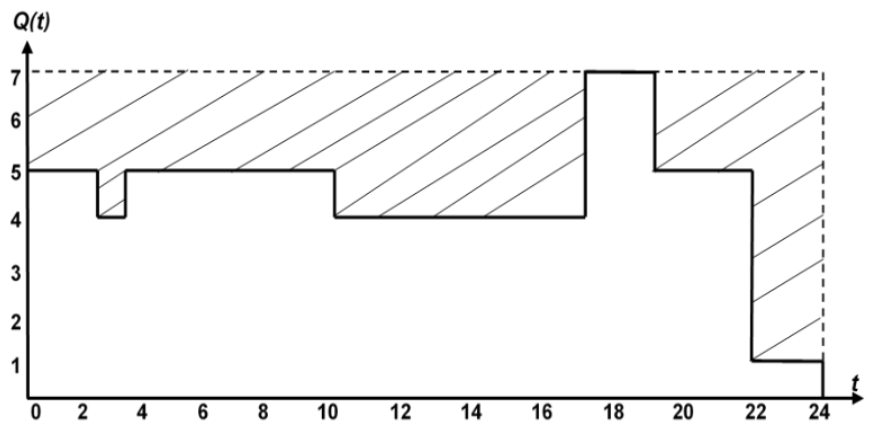

Fig.9. Graph describing the consumption intensity of an unrestricted resource during the work of an innovation project in the preproduction phase of a product innovation.

Source: author's research.

In the resulting schedule, the maximum intensity of resource consumption makes 7 people. Moreover, this maximum was determined by a combination of simultaneously performed project works 4-6 and 3-5. The resulting maximum resource consumption intensity determined the amount of intellectual resource losses. These losses can be reduced by using the 4-6 working time reserve, starting it 2 days later. The total schedule duration will not increase and the maximum total intensity of resource consumption will be 5 people; the resource loss will also be reduced.

When scheduling a project with a limited intellectual resource (Figure 10), conflicts between activities may occur.

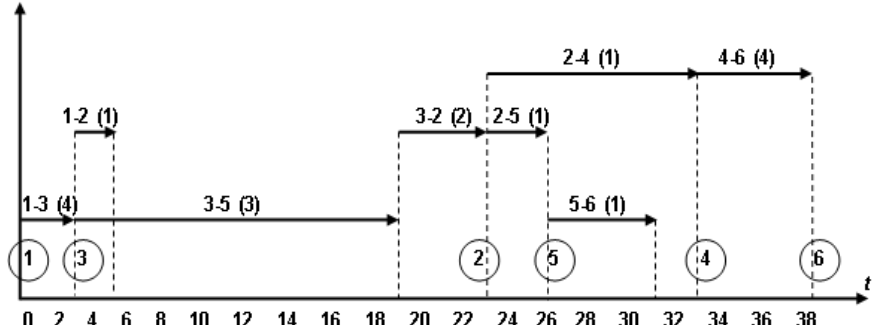

Fig.10. Timetable built for the case of project intellectual resource constraints.

Source: author's research.

To resolve them, it is advisable to use heuristic decisionmaking methods. These methods cover a set of logical techniques and the methods for choosing optimal solutions by theoretical comparison of alternatives, taking into account previously accumulated knowledge. On the basis of heuristic decision-making methods, heuristic strategies are formed that cover a set of heuristic preference rules that are intuitive in nature and combined into a system. Similar heuristic preference rules, which make it possible to determine the priorities of the oriented graph work and the sequence of their inclusion in the schedule, are incorporated into the created software product. According to these rules, tasks that do not have time reserves are included in the schedule first. If the resource is underutilized, the works with the minimum of fulltime reserves will be selected. When total time reserves are matched, the works with the minimum particular time reserves are selected.

When a restriction is imposed on the value of the intellectual resource of an innovative project, the schedule is constructed as follows. At the initial moment of time $(\mathrm{t}=0)$, the works 1-3 and 1-2 apply for inclusion in the schedule. Due to the fact that the total intensity of an intellectual resource consumption by these works exceeds the resource available to a high-tech enterprise, a conflict arises between these works. The first of the heuristic preference rules is applied to resolve the conflict between works. According to this rule, the work 13 is first included in the schedule, since it belongs to the critical path and has no time reserves. When the work 1-3 is performed, the smart resource is fully utilized, so no other network model works can be performed along with the work 1-3.

The result of performing the work $\mathbf{1 - 3}$ is the accomplishment of the 3rd event. After the onset of this event, the work 3-5 and outstanding work 1-2 apply for the schedule inclusion. There is no conflict between these works, since the total intensity of an intellectual resource consumption by these works does not exceed the value of the resource at the disposal of a high-tech enterprise. Therefore, these works are included in the schedule at the same time. To make the 2 nd event happen, you need to do the work 3-2. This activity can only be included in the schedule after the activity 3-5 has been completed, since adding the activity 3-2 to the schedule earlier would result in a conflict between the activities 3-2 and 3-5.

After the onset of the $2 \mathrm{nd}$ event, it is possible to perform the 
works 2-4 and 2-5. There is no conflict between these works, so they can be included in the schedule at the same time. After completing the work 2-5, the 5th event occurs. After this event occurrence, the work 5-6 can be started as it does not conflict with the work 2-4. After completing the work 2-4, the 4th event occurs, and you can start executing the last work 4-6 of the oriented graph.

From the graph shown in Figure 11, it can be seen that the duration of the schedule with the intellectual resource limitation of a high-tech enterprise will be 38 days. The graph of intellectual resource consumption intensity for the project is given in Figure 11.

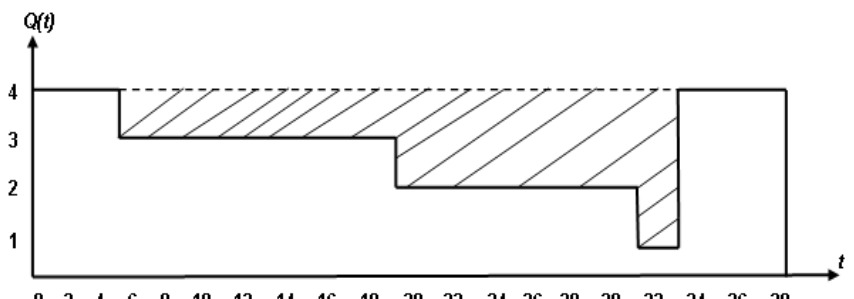

$\begin{array}{llllllllllllllllllll}0 & 2 & 4 & 6 & 8 & 10 & 12 & 14 & 16 & 18 & 20 & 22 & 24 & 26 & 28 & 30 & 32 & 34 & 36 & 38\end{array}$

Fig.11. Graph describing the finite resource consumption intensity when performing work on preparation for the production of product innovations.

Source: author's research.

When the value of the project intellectual resource is limited, the maximum intensity of resource consumption does not exceed a predetermined number of performers involved in the project implementation. In this case, the amount of resource losses will be 44 man-days.

To implement the described algorithm the corresponding calculation mechanism was proposed using the created software package. This mechanism implements the fundamental concepts of the information technology industry, including such paradigms as concatenative, object-oriented, functional paradigms, as well as the latest trends in the development of high-level languages (multivalued logic, functional purity, pattern matching, transparent multithreading, parameter guards), organically combining these features within an intuitive and concise syntax.

The prototype implementation of the algorithm in the highlevel programming language Java demonstrates the high robustness of this model, which makes it possible to reduce the requirements for the initial data quality. This feature is important from the point of view of the method practical implementation within the framework of existing and newly developed resource management systems for innovative projects implemented by Russian high-tech enterprises. A combination of postfix and infix notations is characteristic of the software package developed by us, focused on the use of the high-level Java language. This optimally corresponds to the streaming nature of the computational process in the proposed model to manage the intellectual resources of an innovative project.

\section{CONCLUSION}

The application of oriented graphs and schedule theory in project management enables a high-tech enterprise to visualize the process of intellectual resource management for innovative projects being implemented. In the information environment, network modelling becomes an effective tool for project work and resource scheduling, allowing online project management and control of its implementation. By changing the network model parameters, it is possible to manage the schedule of the innovative project and optimize the loss of its intellectual resource.

At that, the task of innovative project management implemented under the conditions of a high level of uncertainty and risk becomes very urgent. In this case, the management of such projects is advisable to build on the basis of using both deterministic models with probabilistic time parameters and stochastic network models. The transition to stochastic networks is necessary when they develop complex innovative projects that have no analogues. In such projects, uncertainty manifests itself not only in the probabilistic parameters of operation duration, but also in the probabilistic nature of the organizational structure that implements the project management process. The resulting uncertainty determines the emergence of a sufficiently large set of possible options to achieve intermediate and final results of project activity.

The use of the original software package for the intellectual resource management of an innovative project implemented by a high-tech enterprise can reduce the time for creating a network model, calculating its parameters and building the schedule, and increase the reliability of the decisions made when choosing the best option for the use of intellectual project resources.

\section{References}

[1] M. Batova, V. Baranov, S. Mayorov and K. Zhao, "Informatisation of Project Activities Performed by Innovation Clusters of the Kamsky Agglomeration in Russia" (Periodical style-Accepted for publication), Conference Proceedings 2021 Asia-Pacific Conference on Communications Technology and Computer Science (ACCTCS), 2224 January 2021, to be published.

[2] R. Cole and E. Scotcher, Brilliant Agile Project Management: A Practical Guide to Using Agile, Scrum and Kanban. Harlow: Pearson, 2015.

[3] A. Stellman and J. Greene, Head First Agile: A BrainFriendly Guide to Agile Principles, Ideas, and Real-World Practices. USA, Sebastopol CA: O'Reilly Media, Inc., 2017.

[4] J. Sutherland, Scrum: The Art of Doing Twice the Work in Half the Time. USA, New York: Crown Business Publications, 2014.

[5] R. J. Martinelli and D. Z. Milosevic, Project Management ToolBox: Tools and Techniques for the Practicing Project Manager, 2nd ed. New Jersey: John Willey\&Sons, 2016. 
[6] V.A. Pervushin, Practice of Innovation Project Management. Moscow: Delo, 2013. (in Russian).

[7] L.I. Rudenko, Fundamentals of Project Management. Simferopol: Publishing house of KFU named after V.I. Vernadsky, 2018. (in Russian).

[8] H. Kerzner, Innovation Project Management: Methods, Case Studies, and Tools for Managing Innovation Projects. New Jersey: John Willey\&Sons, 2019.

[9] E.A. Sosnin, Managing Innovation Projects. Rostov-onDon: Phoenix, 2018. (in Russian).

[10] R.T. Kreutzer, Innovative Project Management Tools. In: Toolbox for Marketing and Management. Management for Professionals. Springer, Cham. 2019. https://doi.org/10.1007/978-3-030-13823-3_8.

[11] M. Batova, V. Baranov, and S. Mayorov, "Automation of Economic Activity Management of High-Tech Structures of Innovation-Oriented Clusters" (Periodical styleAccepted for publication 04.10.2020), Journal of Industrial Integration and Management. https://doi.org/10.1142/S2424862220500256, to be published.

[12] M.M. Batova, "Formation of information and intellectual capital in the system "education-science-production", Property relations in the Russian Federation, No.8(227), 2020. (in Russian).

[13] M.M. Batova, "Formation of digital competencies in the "education-science-production" system", Issues of innovative economy, Vol.10, No.4, 2019. doi: 10.18334/vinec.9.4.41467. (in Russian).

[14] I. V. Baranova, M. M. Batova and K. Zhao. Information tools for digital transformation of high-tech enterprises. Moscow: $\quad$ Creative Economy, 2020. doi: 10.18334/9785912923098. (in Russian).

[15] M. M. Batova, I. V. Baranova, S. V. Mayorov and O. V. Korobchenko. "Methodology and practical tools of digital transformation of high-tech enterprises", MIR (Modernization. Innovation. Development), 10(4), 2019. (in Russian).

[16] Y.V. Butsenko, "The Analysis of Investment Project Management Software", Applied Management, No.1(65), 2017. (in Russian).

[17] A Guide to the Project Management Body of Knowledge (PMBOK Guide) 6th ed., Newtown Square PA: Project Management Institute, 2017.

[18] Organizational Project Management Maturity Model (OPM3). Knowledge Foundation 3rd ed., Newtown Square PA: Project Management Institute, 2018.

[19]D.I. Golenko-Ginzburg, Stochastic network models of planning and management. Voronezh: Nauchnaya kniga, 2010. (in Russian).

[20] M.A. Pleskunov, Network planning tasks. Yekaterinburg: Urals University Press, 2014. (in Russian).

[21]A.S. Vorontsova, Methodology for scheduling-network and resource planning and management in a project organization. Moscow: Izdanie knig.com, 2019. (in Russian).

[22] A.A. Lazarev and E.R. Gafarov, Schedule Theory: Tasks and Algorithms. Moscow: Lomonosov Moscow State University Press, 2011. (in Russian).
[23] S. Gawiejnowicz, Models and Algorithms of TimeDependent Scheduling. Monographs in Theoretical Computer Science. An EATCS Series. Berlin, Heidelberg: Springer, 2020. https://doi.org/10.1007/9783-662-59362-2.

[24]E. Gonsalves, Beginning Java EE 7. New York: Apress, 2013.

[25]H. Shildt, The complete reference Java (10th ed.). New York: Oracle Press - McGraw-Hill Education, 2018.

[26] T.S. Mashnin, Java FX 2.0. Development of RIAapplications. Saint Petersburg: BXV-Peterburg, 2012. (in Russian).

[27] T.S. Mashnin, Web-services Java. Saint Petersburg: BXV-Peterburg, 2012. (in Russian).

[28] C. Castillo and Y. Joan, JavaFX Scene Builder. Getting Started with JavaFX Scene Builder. Release 2.0. Oracle America, Inc., 2014

[29] J. Bloch, Effective Java, 3th ed. Pearson Addison-Wesley, 2019.

[30]C. S. Horstmann, Core Java, Volume II--Advanced Features, 11th ed. Boston: Addison-Wesley Professional, 2018.

[31]R. Diestel, Graph Theory. Berlin Heidelberg: SpringerVerlag, 2017. doi: 10.1007/978-3-662-53622-3.

\section{Creative Commons Attribution License 4.0 (Attribution 4.0 International, CC BY 4.0)}

This article is published under the terms of the Creative Commons Attribution License 4.0 https://creativecommons.org/licenses/by/4.0/deed.en_US 